\title{
Prevalence and patterns of adverse events following immunisation among children less than 24 months attending immunisation clinics in Kano, Nigeria
}

\author{
Hajara I. Maizare, ${ }^{1}$ Fatimah I. Tsiga-Ahmed, ${ }^{2}$ Abubakar M. Jibo, ${ }^{2}$ Aishatu L. Adamu, ${ }^{2}$ \\ Rabiu I. Jalo, ${ }^{2}$ Abubakar Magaji, ${ }^{3}$ Umma A. Ibrahim, ${ }^{4}$ Auwalu U. Gajida ${ }^{2}$ \\ ${ }^{1}$ Department of Community Medicine, Aminu Kano Teaching Hospital, Kano; ${ }^{2}$ Department of Community \\ Medicine, Bayero University/Aminu Kano Teaching Hospital, Kano; ${ }^{3}$ Hospitals Management Board, \\ Ministry of Health Bauchi, Bauchi State; ${ }^{4}$ Department of Paediatrics, Bayero University/Aminu Kano \\ Teaching Hospital, Kano, Nigeria
}

\author{
Correspondence: Fatimah I. Tsiga-Ahmed, Department of Community \\ Medicine, College of Health Sciences, Bayero University Kano/Aminu \\ Kano Teaching Hospital, Zaria Road, Kano, Nigeria. \\ Tel.: 08033148264. \\ E-mail: fitsiga.cmed@buk.edu.ng
}

Key words: Adverse events; immunisation; prevalence; pattern; children.

Acknowledgements: The authors thank Kano State Primary Healthcare Management Board for permitting this study.

Contributions: Concept: HIM, FIT, AM, UAI, AUG; Design: HIM, FIT, AMJ; Definition of intellectual content: AMJ, ALA, RIJ; Literature search: FIT, RIJ, AM; Data acquisition: HIM, FIT, UAI, AUG; Data analysis: HIM, ALA, RIJ, AM; Manuscript preparation: HIM, FIT, ALA, AUG; Manuscript editing: AMJ, ALA, RIJ; Manuscript review: AMJ, ALA, UAI, AG; Guarantor: FIT.

Conflicts of interest: The authors declare no conflicts of interest.

Availability of data and materials: All data generated or analyzed during this study are included in this published article.

Ethics approval and consent to participate: The Ethics Committees of Kano State Ministry of Health and the Primary Health Care Management Board approved this study (MOH/OFF/797/T.I/1168). The study is conformed with the Helsinki Declaration of 1964, as revised in 2013, concerning human and animal rights. All participants provided written or thumb-printed informed consent in the presence of a witness (a nurse). Confidentiality in reporting qualitative findings was ensured by removing identifiers.

Informed consent: Written informed consent was obtained from a legally authorized representative(s) for anonymized patient information to be published in this article.

Received for publication: 7 July 2021.

Revision received: 6 October 2021.

Accepted for publication: 6 October 2021.

This work is licensed under a Creative Commons Attribution NonCommercial 4.0 License (CC BY-NC 4.0).

${ }^{\circ}$ Copyright: the Author(s),2021

Licensee PAGEPress, Italy

Annals of African Medical Research 2021; 4:149

doi:10.4081/aamr.2021.149

\begin{abstract}
Adverse Events Following Immunisation (AEFI) contribute to child morbidity and mortality as they often lead to low uptake of vaccines with consequent persistence of vaccine-preventable diseases. It is essential to assess the prevalence of AEFIs in northern Nigeria, where misconceptions about immunisation exist. This study assessed the prevalence and pattern of AEFI among children less than 24 months after attending immunisation clinics in Kano, Nigeria. Using a mixed-methods design, adapted intervieweradministered questionnaires were assigned to a cross-section of 384 mother-baby pairs who presented to the immunisation clinics of selected primary healthcare centres (PHCs) within metropolitan Kano. This was followed by six sessions of focus group discussion with a sub-sample of the mothers. Logistic regression and the framework approach were used to analyse the data. The prevalence of AEFI was $(43.5 \%, n=164)$, and most cases $(72.4 \%, n=273)$ were mild. Fever was the most common type of AEFI reported $(66.5 \%$, $\mathrm{n}=109$ ) and was higher among infants less than three months $(44.5 \%, \mathrm{n}=73)$. Age of the index child was the only significant predictor of AEFI (OR:0.18, 95\% CI: 0.10-0.35). Our study shows that AEFI was common among children less than 24 months old in Kano. We recommend sensitisation and health education of caregivers using valuable communication strategies and sufficient training of immunisation service providers on professional ways to deliver these vaccines safely.
\end{abstract}

\section{Introduction}

Immunisation has been identified as one of the most costeffective interventions in healthcare delivery. ${ }^{1,2}$ The World Health Organization (WHO) reported that vaccination saves two to three million lives every year, and $29 \%$ of deaths among children aged 1-59 months are vaccine-preventable. ${ }^{3,4}$ Advances in vaccines have led to an improvement in the health of individuals, communities and nations, as well as a decline in the incidence of diseases, disability and death from vaccine-preventable diseases worldwide. $^{5,6}$

Despite the best efforts of medical science, manufacturers, regulators, health authorities and medical practitioners to ensure vaccine safety, it is well acknowledged that there are inherent risks associated with the administration of these vaccines. ${ }^{4}$ An Adverse Event Following Immunisation (AEFI) is a medical incident after an immunisation, causes concern and is believed to be caused by immunisation. ${ }^{2,5}$ If AEFIs are not rapidly and effectively dealt 
with, they can cause vaccination misconceptions among caregivers of children and ultimately result in vaccine hesitancy with a consequent decline in uptake of routine childhood immunisation. , $^{3,5}$

AEFIs may occur from programme error during vaccine preparation, handling and circumstances surrounding the administration of vaccines. ${ }^{5,7}$ AEFIs are classified by frequency as rare, for example, death or common such as fever. ${ }^{8}$ They could also be classified by locality into local or systemic, by disease severity into mild or severe, by causality into a vaccine or non-vaccine related causes, by preventability into intrinsic to a vaccine, faulty production and faulty administration and by pathophysiology (stabilisers, immune potentiators, or antibiotics which are included in the vaccines may cause an adverse reaction to susceptible vaccines). $., 9,10$ The frequency of reactions is related to the degree of purity of toxoid, the dose of antigen, the number of previous booster doses and spacing of the last dose. ${ }^{8}$

Although AEFI has been well known in developed countries, in recent decades, the cases of AEFI in low and middle-income countries have become more common, possibly due to the increase in vaccine utilisation and improvement in awareness and notification. ${ }^{5}$ A study from Brazil reported an AEFI rate of 6.76 adverse events per 100,000 doses; $45.1 \%$ were related to the tetravalent conjugate vaccine, and $37.4 \%$ were due to the pentavalent vaccines. ${ }^{9}$ In India, the incidence of AEFI was $13.7 \%$, with fever being the most frequently mentioned. ${ }^{11}$ In Africa, where systems and practices for identifying and reporting AEFIs are not well developed and underutilised, the annual reporting rate of AEFIs in Zimbabwe was 0.58 per 100,000 vaccine doses, and reporting ratio ranged between 0 and 30.2 AEFI reports per 100,000 surviving infants. ${ }^{12}$ In Nigeria, a prevalence of $34.9 \%$ to $46.5 \%$ was reported across different parts of the country. $7,13,14$

This study assessed the prevalence and patterns of adverse events following immunisation among children in Kano, Nigeria. Findings from this study could be helpful for health care providers, immunisation programme managers, and development partners supporting the programme in preparing strategies for improved management of the immunisation programme in Nigeria.

\section{Materials and Methods}

\section{Study design}

The study was a hospital-based, descriptive cross-sectional with a concurrent mixed method of data collection.

\section{Study setting}

Kano is a state located in North-western Nigeria with 44 administrative local government areas, 8 of which form the Kano Metropolitan Area, the locale for this study. The State's 2021 estimated population of $13,999,782$, projected at $2.6 \%$ per annum growth from the 2006 census. Children under five years make up $20 \%$ of the population, with an infant mortality rate of 62 per 1,000 live births, a child mortality rate of 109 per 1,000 children surviving to age 12 months and an under-5 mortality rate of 164 per 1,000 live births. ${ }^{15}$ The proportion of children aged 12-23 months in Kano state who received all vaccinations recommended in the immunisation schedule by their first birthday was $10 \%{ }^{16}$

There are 970 Primary Health Care facilities within the State, 704 of which provide routine Immunisation services, with a varying schedule and frequency per week.

\section{Sampling technique}

The minimum sample size was computed using the formula for calculating single population proportions, ${ }^{17}$ prevalence of AEFI from a previous study in Kano (34.9\%), ${ }^{7} 95 \%$ confidence interval, and tolerable error of $5 \%$. The final sample size of 384 was obtained after adjusting by $10 \%$ to account for non-response.

A three-stage sampling technique was used to select eligible respondents. Four of the eight metropolitan LGAs were chosen using a simple random process (balloting) in the first stage. Two primary health centres (PHCs) were then selected out of the eight selected LGAs, using simple random sampling technique. The average monthly turn out of patients for the selected PHCs was obtained, and a proportional allocation of respondents was done to each PHC. Respondents were then selected by systematic sampling at each PHC. Participants with homogenous socio-demographic characteristics were purposively selected for FGDs.

\section{Study population}

The study population were mothers of children less than 24 months attending immunisation clinics of the selected PHCs and babies that presented for at least a second immunisation visit. A foster mother or caregiver was included if she had the requested information in addition to playing major decision roles in the dayto-day care of the child. Mothers of children with missing immunisation cards and seriously sick children were excluded from the study. The study was limited to caregivers of children aged less than 24 months, as children at this age are expected to have received all the essential doses of immunisation.

\section{Study instrument and data collection}

A pre-tested structured interviewer-administered questionnaire adapted from previous studies was used to obtain information from eligible respondents. ${ }^{7}$ Data were collected on socio-demographic characteristics of the index children and their caregivers and prevalence and pattern of adverse events following immunisation. A $10 \%$ sample was used to pre-test and assess the psychometric properties (re-validation and reliability) of the questionnaires in other PHCs not among those selected. All scales were reliable and sections consistent, with Cronbach's alpha of $\geq 0.80$.

A qualitative interview guide was used to steer the FGDs, and it had open-ended questions with probes for detailed descriptions. Participants for the FGDs were caregivers of the children who consented and were selected from the chosen PHCs. These participants were stratified into homogenous groups of 8-10 based on their age and parity. The FGDs were conducted at a serene venue within the selected hospitals. Standard FGD procedures were followed; a group moderator (one of the authors) led the session, accompanied by a note-taker and timekeeper (another author) that monitored time and recorded the interviews using a digital voice recorder. A total of 6 FGDs were conducted, each session lasting between 30-45 minutes before saturation was reached.

\section{Outcome variable}

Adverse event following immunisation was defined as any medical incident that takes place after an immunisation, causes concern and is believed to be induced by immunisation.

\section{Statistical analysis}

Data were coded and entered into a spreadsheet on Microsoft excel and analysed using Statistical Package for the Social Sciences (SPSS) Statistical Software version 20 (IBM Corp., Armonk, NY). Quantitative variables were summarised and pre- 
sented using mean and Standard Deviation (SD), while qualitative variables were summarised and presented using frequencies and percentages. Pearson's Chi-square test was used to assess significant associations between the socio-demographic characteristics of the baby and the occurrence of AEFI. Binary logistic regression was used to ascertain the independent effect of all explanatory variables on the presence of AEFI. Type I error was fixed at 5\% for all tests.

\section{Qualitative data analysis}

Focus group discussions were recorded and transcribed verbatim, including gestures, and analyses were done manually using MS Word and MS Excel. For validation, all FGD recordings were transcribed in their original languages (Hausa), translated into English, and back-translated into Hausa. Thematic analysis was performed based on the framework approach and included familiarisation through repeated reading, coding, theme generation, applying the codes to the transcripts, matrix formation, and interpretation. Findings from the two components of the mixed-methods study were triangulated.

\section{Ethical Considerations}

Ethical approval was sought from the Kano State Ministry of Health and permission from the Primary Health Care Management Board (Reference-MOH/OFF/797/T.I/1168). Participants were given adequate information on the study in their language of understanding, ensuring that they comprehended the information provided. They were allowed to raise concerns, and participation was made entirely voluntary. All participants provided written or thumb-printed informed consent in the presence of a witness (a nurse). Confidentiality in reporting qualitative findings was ensured by removing identifiers.

\section{Results}

A total of 384 respondents were approached, of which 377 questionnaires were correctly filled, giving a response rate of $98.9 \%$.

Table 1 summarises the socio-demographic characteristics of mother/baby pairs included in the study. The mean age $( \pm \mathrm{SD})$ of the infants studied was $4.4( \pm 2.8)$ months, and almost half were less than three months old $(49.3 \%, \mathrm{n}=186)$. The majority were males $(53.3 \%, \mathrm{n}=201)$, delivered in the hospital $(56.0 \%, \mathrm{n}=211)$ and of second $(32.9 \%, \mathrm{n}=124)$ birth order. The mean age $( \pm \mathrm{SD})$ of mothers studied was $26.4( \pm 6.0)$ years, and more than half $(61.5 \%$, $\mathrm{n}=232$ ) were educated up to secondary school. Nearly two-thirds $(63.7 \%, n=240)$ of the mothers were of Hausa ethnic group, $64.2 \%$ $(n=242)$ were income earners and about a third $(34.2 \%, n=129)$ had at least four living children.

The overall prevalence of AEFI was found to be $43.5 \%$ $(n=164)$. Most $(72.4 \%, n=165)$ of the AEFI cases were mild, with fever $(66.5 \%, n=109)$ being the most frequently mentioned systemic AEFI among the respondents (Table 2). Themes from focus group discussions confirmed fever as a common AEFI in addition to other symptoms as shown below:

"This is my third baby, and every time she receives an immunisation, she comes down with fever and excessive crying." $27-$ years-old mother of three

"As soon as my child is immunised, their body becomes hot, especially at night. This fever lasts between one to two days." 20 years-old mother of one

"After the last injection we had, my child could not crawl for five days because the place was swollen, and we were asked to put ice." 35-years-old mother of five

AEFI was more common among children less than 3 months $(44.5 \%, \mathrm{n}=73)$, males $(54.3 \%, \mathrm{n}=89)$, of second or third birth order $(32.8 \%, \mathrm{n}=54)$ and babies delivered in the hospital $(55.5 \%, \mathrm{n}=91)$. The occurrence of AEFI among younger babies was a recurrent

Table 1. Socio-demographic characteristics of mother/baby pairs $\mathrm{N}=377$.

\begin{tabular}{lc} 
Characteristic & Frequency (\%) \\
Characteristics of child & \\
Age (months) & \\
3 & $186(49.3)$ \\
$4-6$ & $117(31.1)$ \\
7 & $74(19.6)$ \\
Sex & \\
Male & $201(53.3)$ \\
Female & $176(46.7)$ \\
\hline Place of delivery & \\
Home & $166(44.0)$ \\
Hospital & $211(56.0)$ \\
Health status & \\
Healthy & $368(97.6)$ \\
Unhealthy & $9(2.4)$ \\
Birth order & \\
1 & $102(27.1)$ \\
2 & $124(32.9)$ \\
3 & $93(24.6)$ \\
$\geq 4$ & $58(15.4)$ \\
Characteristics of caregivers
\end{tabular}

Age (years)

$15-24 \quad 165(43.8)$

$25-34 \quad 169(44.8)$

$35-44$

$40(10.6)$

45

$3(0.8)$

Mean \pm SD

$26.4 \pm 6.02$

Ethnicity

Hausa

Fulani

Others

240 (63.7)

$74(19.6)$

Marital Status

Married

Divorced

$371(98.4)$

Occupation

Income earners

$6(1.6)$

Non-Income earner

$242(64.2)$

Educational status

Non-formal 54 (14.3)

Primary

$42(11.1)$

Secondary

232 (61.5)

Tertiary

49 (13.1)

$\begin{array}{lc}\text { Antenatal care attendance } & 373(98.9) \\ \text { Yes } & 4(1.1)\end{array}$

Number of living children

$\begin{array}{ll}1 & 121(32.1) \\ 2-3 & 127(33.7) \\ \geq 4 & 129(34.2)\end{array}$


theme during the discussions:

"It is a rule that those first two injections must always induce a severe fever in my children for at least 24 hours." 38-years-old mother of eight

"One thing I have noticed is that as they grow older, the side effects of the vaccine become less severe. I don't know why." 33year-old mother of six

"After the first vaccine, my whole family did not sleep. My husband was distraught and said it was the injection. He kept saying the children were too young to receive any injection. But after the second and third injections, my baby just had a mild fever." 19years-old mother of two

Following bivariate analysis, the occurrence of AEFI was found to be significantly associated with the age of the infants $(\mathrm{p}=$ 0.002), but not with gender, health status, place of delivery, birth order or the number of living siblings (Table 3). Odds of AEFI were found to be $82 \%$ lower among respondents aged 4 to 6 months compared to those three months and below $0.18(0.10-$ 0.35; Table 4).

\section{Discussion}

This study assessed the prevalence and patterns of adverse events following immunisation among children less than 24 months attending immunisation clinics in the Kano metropolis. We found that almost one in two children had a form of AEFI after their last immunisation. Fever was the most common AEFI reported, and the child's age was the only predictor of the occurrence of AEFI.

The prevalence of AEFI reported in this study is at par with figures reported from a previous study in north-central Nigeria ${ }^{13}$ and southern Nigeria. ${ }^{14}$ Astonishingly, our figures were higher than results from an earlier study in our setting, ${ }^{7}$ and from findings in a similar study from India. ${ }^{11}$ While intercountry differences in the prevalence of AEFI could be explained by variations in the type of vaccine, manufacturer, handling and storage techniques, genetic and racial predispositions, the disparity in findings from our setting is uncertain. Perhaps, varying vaccination coverage levels between then and now and a temporal difference in awareness of AEFI. Additionally, all forms of AEFI were considered for this research, not only severe conditions that are commonly reported.

The patterns of AEFI mainly reported by most of the respondents from this study were systemic and mild; mostly fever, painful swelling at the injection site and excessive cry as reported by similar studies. 7,18,19 The fever and painful swelling were usually of short duration and were managed by reassuring and educating parents on why AEFI occurs and what should be done if it occurs. This is not unexpected, considering the vaccination process involves the introduction of antigens into the body to produce immunologic reactions preparing the body for subsequent infections. Fever after vaccination typically arises from a complex physiologic reaction stemming from the production of endogenous cytokines in response to inoculated substances.

Cases of AEFI were more common among children $£ 3$ months of age. This corresponds to the period by which the pentavalent vaccines (1-3) are given, and an increase in incidents of AEFI has

Table 2. Pattern of adverse events following immunisation among respondents.

\begin{tabular}{lc} 
Characteristic & Frequency (\%) \\
$\begin{array}{l}\text { (a) Locality } \\
\text { Local }\end{array}$ \\
$\quad$ Pain and swelling at the injection site & $52(31.7)^{\#}$ \\
Systemic & $109(66.5)^{\#}$ \\
$\quad$ Fever & $63(38.4)^{\#}$ \\
$\quad$ Persistent inconsolable cry & $4(2.4)^{*}$ \\
$\quad$ Others* & \\
\hline (b) Severity & $165(72.4)^{\#}$ \\
Mild & $63(27.6)^{\#}$ \\
Severe &
\end{tabular}

\# Multiple responses *0thers (diarrhoea, vomiting, rashes).

Table 3. Factors associated with the occurrence of adverse events following immunisation among the respondents.

\begin{tabular}{|c|c|c|c|c|}
\hline $\begin{array}{l}\text { Socio-demographic characteristics } \\
\text { of the index child }\end{array}$ & Subgroup & \multicolumn{2}{|c|}{$\begin{array}{l}\text { Experience of AEFI during the preceding visit } \\
\begin{array}{cc}\text { Yes } \mathrm{N}=164 & \text { No } \mathrm{N}=213 \\
\mathrm{n}(\%) & \mathrm{n}(\%)\end{array}\end{array}$} & P-value \\
\hline Age of child (months) & $\begin{array}{l}\leq 3 \\
4-6 \\
\geq 7\end{array}$ & $\begin{array}{l}73(44.5) \\
66(40.3) \\
25(15.2)\end{array}$ & $\begin{array}{l}113(53.1) \\
51(23.9) \\
49(23.0)\end{array}$ & $0.002 *$ \\
\hline Sex & $\begin{array}{l}\text { Male } \\
\text { Female }\end{array}$ & $\begin{array}{l}89(54.3) \\
75(45.7)\end{array}$ & $\begin{array}{l}112(52.6) \\
101(47.4)\end{array}$ & 0.7 \\
\hline Place of Delivery & $\begin{array}{l}\text { Home } \\
\text { Hospital }\end{array}$ & $\begin{array}{l}73(44.5) \\
91(55.5)\end{array}$ & $\begin{array}{c}93(43.7) \\
120(56.3)\end{array}$ & 0.9 \\
\hline Birth order & $\begin{array}{l}1 \\
2-3 \\
4-6 \\
\geq 7\end{array}$ & $\begin{array}{l}45(27.5) \\
54(32.8) \\
37(22.6) \\
28(17.1)\end{array}$ & $\begin{array}{l}57(26.8) \\
70(32.8) \\
56(26.3) \\
30(14.1)\end{array}$ & 0.8 \\
\hline No of living siblings & $\begin{array}{l}1 \\
2-3 \\
4-12\end{array}$ & $\begin{array}{l}54(33.0) \\
55(33.5) \\
55(33.5)\end{array}$ & $\begin{array}{l}67(31.5) \\
72(33.8) \\
74(34.7)\end{array}$ & 0.9 \\
\hline Health status & $\begin{array}{l}\text { Healthy } \\
\text { Unhealthy }\end{array}$ & $\begin{array}{c}158(96.3) \\
6(3.7)\end{array}$ & $\begin{array}{c}210(98.6) \\
3(1.4)\end{array}$ & 0.5 \\
\hline
\end{tabular}


Table 4. Predictor of adverse events following immunisation.

\begin{tabular}{llc} 
Characteristic & OR $(95 \%$ Confidence Interval) & P-value \\
Age (months) & & \\
$\leq 3$ & Reference & \\
$4-6$ & $0.18(0.10-0.35)$ & 0.001 \\
$\geq 7$ & $1.7(0.97-3.16)$ & \\
\hline
\end{tabular}

been associated with Diphtheria, Pertussis and Tetanus (DPT) containing vaccines. ${ }^{2,9,20}$ Similar findings suggest that in this age group, there is a higher concentration of vaccines applied, and the immune system is still immature, increasing the probability of infectious processes, allergies, and clinical alterations that may be associated with immunisation. ${ }^{9}$

A relationship between AEFI and gender has been documented, and immunological, hormonal and genetic factors have been implicated. ${ }^{19}$ Despite the slight predominance of males in the occurrence of AEFI in our study, no statistically significant difference was observed between the two categories of gender. Our study found that most of the children were healthy when they presented for the immunisation; however, AEFI was more prevalent among healthy children when they presented for immunisation than those who were not healthy when immunised. It is possible that features of AEFI could be mistaken for the symptoms or signs of the concurrent illness. Furthermore, the prevalence of AEFI was higher among those babies delivered in the hospital. Delivery in a health facility avails mothers the opportunity to immunise their babies, which will increase the number of children vaccinated and hence the higher occurrence of AEFI. ${ }^{18,21}$

Interpretations of findings from this study must be viewed within its strengths and limitations. A significant strength is the mixed property of quantitative and qualitative data providing a thorough understanding of caregivers' perspectives on AEFI. A limitation may be the hospital-based source of participants for the study, restricting the ability of the research to capture a more significant portion of the population that do not come to these facilities, ultimately affecting the generalizability of the study results. Future research efforts in this community should study vaccinerelated risk factors for AEFI and the effect of AEFI on subsequent vaccination timeliness.

\section{Conclusions}

We found a high prevalence of AEFI among children less than 24 months old attending PHCs in Kano metropolis. The age of the child at immunisation influenced the occurrence of AEFI. The qualitative component further described caregivers' experience regarding the types of AEFI seen and the time of the event. We recommend sensitisation and health education of caregivers using valuable communication strategies and sufficient training of immunisation service providers on professional ways to deliver these vaccines safely. The need to strengthen AEFI monitoring and reporting systems in PHCs within Kano cannot be overemphasised.

\section{References}

1. Legesse E, Dechasa W. An assessment of child immunisation coverage and its determinants in Sinana District, Southeast.
BMC Pediatrics 2015;15:1-14.

2. Nisarg DJ, Hiren KP, Krunal CS, et. al. Pattern of adverse events following immunisation in an Indian Teaching Hospital. Int J Med Sci Public Health 2013;2:62-8.

3. Ogunyemi RA, Odusanya OO. A survey of knowledge and reporting practices of primary healthcare workers on adverse experiences following immunisation in Alimosho local government area, Lagos. Niger Postgrad Med J 2016;23:79-85.

4. Hu Y, Qian L Q, Luoya LL, et al. Surveillance for adverse events following immunisation from 2008 to 2011 in Zhejiang Province, China. Am Soc Microbiol 2013;20:211-7

5. World Health Organization. Causality assessment of an adverse event following immunisation (AEFI): user manual for the revised WHO classification (Second edition). Geneva: 2018. Accessed March 2021. Available from: https://www.who.int/publications/i/item/causality-assessmentaefi-user-manual-2019

6. Choe Y. J, Bae G. Management of vaccine safety in Korea. Clin Exp Vaccine Res 2013;2:40-5.

7. Lawan UM, Amole GT, Wali NY, et al. Pattern of adverse events following immunisation in nourished and malnourished infants in Kano, North-Western Nigeria. Sahel Med J 2016;19:131-6.

8. Mort M, Baleta A, Destefano F, et al. World Health Organization. Vaccine safety basics: learning manual. World Health Organization; 2013.

9. Santos MC, Netto P. Prevalence and factors associated with the occurrence of adverse events following immunisation in children. Acta Paul Enferm 2016;9:626-32.

10. Yu H, Yaping C. Completeness and timeliness of vaccination and determinants for low and late uptake among young children in eastern China. Hum Vaccin Immunother 2014;10:1408-15.

11. Sebastian J, Gurumurthy P, Ravi MD, Ramesh M. Active surveillance of adverse events following immunisation (AEFI): a prospective 3-year vaccine safety study. Ther Adv Vaccines Immunother 2019;21;7:2515135519889000.

12. Masuka JT, Khoza S. Adverse events following immunisation (AEFI) reports from the Zimbabwe expanded programme on immunisation (ZEPI): an analysis of spontaneous reports in Vigibase ${ }^{\circledR}$ from 1997 to 2017. BMC Public Health 2019;19:1166.

13. Afolaranmi TO, Hassan ZI, Sodipo OY, et al. Knowledge of adverse events following immunisation, its prevalence and actions of mothers of children aged 0-23 months in a tertiary health institution in Jos, North Central Nigeria. J Med Trop 2020;22:57-64.

14. Adam VY, Onowugbeda ED, Osuji OI, Omohwovo OD. Prevalence and management of perceived adverse events following immunisation in infants attending Well Baby Clinics in Benin City, Nigeria. J Comm Med Pri Health Care 2020;32:5767.

15. National Population Commission (Nigeria) and ICF International. Nigeria Demographic and Health Survey 2018. Abuja, Nigeria, and Rockville, Maryland, USA: NPC and ICF; 2019.

16. National Bureau of Statistics (NBS) and United Nations Children's Fund (UNICEF). 2017 Multiple Indicator Cluster Survey 2016-17, Survey Findings Report. Abuja, Nigeria: Accessed June 2021. Available from: https://www.unicef.org/nigeria/reports/multiple-indicatorcluster-survey-2016-17-mics

17. Ajay S, Micah B. Sampling techniques \& determination of 
sample size in applied statistics research: An overview. Int J Econ Commerce Manage 2014;11:1-22.

18. Tsafack, M, Ateudjieu, J. Improving community-based AEFI (Adverse events following immunisation) reporting rate through telephone 'beep' in a Cameroon health district: A randomised field trial. Pan Afr Med J 2015;22:1-7.

19. Mohammad S, Zaidi A, Khowaja S, et al. Evidence from the Demographic and Health Survey Coverage; timeliness and determinants of immunisation completion in Pakistan. Hum Vaccin Immunother 2014;10:1712-20.

20. Harris T, Nair J, Fediurek J, Deeks SL. Assessment of sex-specific differences in adverse events following immunisation reporting in Ontario. Vaccin 2017;35:2600-4.

21. Adebayo BE, Oladokun RE. Immunisation coverage in a rural community in southwestern Nigeria. Vaccin 2012;3:20. 